\title{
LAS MEDIDAS CONSERVATIVAS COMO PARTE INTEGRANTE DE LA ESTRUCTURA DEL EMBARGO
}

\author{
PRECAUTIONARY MEASURES AS PART OF SEIZURE
}

\begin{abstract}
Alberto GonZÁLEZ VIDAL*
RESUMEN: El presente trabajo trata acerca de si la medida conservativa de la anotación registral de la traba sobre bienes inmuebles o derechos reales constituidos sobre ellos forma o no parte integrante de la estructura del embargo. Comienza con un examen de los antecedentes históricos de la normativa aplicable, para luego presentar el estado actual de la discusión, finalizando con las razones por las que debemos concluir que esta medida tiene esencial relevancia para que el embargo produzca eficazmente todos sus efectos. Este análisis se ha efectuado considerando los efectos prácticos que la solución trae aparejada, especialmente en relación al ejecutante y a los terceros.
\end{abstract}

Palabras clave: proceso civil, embargo, estructura, anotación registral, finalidad conservativa.

ABSTRACT: This work treats the discussion on whether or not the registration (with the Real Estate Conservative's office) of a judicial order of seizure on real estate or in in-rem rights on them, forms part of the seizure's structure. We begin with an analysis of the applicable laws' historical background, thereafter setting the current stage of discussions on the matter, and finally explaining the reasons why we should conclude that this measure has essential relevant for the seizure to effectively produce all its effects. This analysis has been made considering practical considerations and effects, especially regarding the foreclosing party, and third parties as well.

Key words: civil process, seizure, structure, registration with the Conservative's office, conservative purpose.

\section{INTRODUCCIÓN}

En este trabajo pretendemos abordar una de las cuestiones más discutidas en torno al embargo. Esto es, si las medidas conservativas forman o no parte integrante de su estructura. La solución no es fácil, y trae aparejada radicales consecuencias prácticas.

La gran mayoría de los autores atribuye al embargo una función esencialmente ejecutiva. Esto es, la traba tiene por objeto determinar qué bien, dentro de aquellos que el ejecutado es dueño, debe responder del crédito insoluto; de modo que el embargo se constituye en la sola declaración judicial destinada a fijar el bien o derecho sobre el que se desarrollará la actividad ejecutiva.

* Licenciado en Ciencias Jurídicas por la Universidad de Los Andes, Abogado. Alumno del programa de Doctorado en Derecho de la Universidad de Los Andes. Correo electrónico: agonzalezv@prieto.cl 
Sostenemos que el embargo también tiene una finalidad conservativa: dota al ejecutante de la seguridad de que el bien afectado no desaparecerá material ni jurídicamente. Esta finalidad, tal vez más evidente que la ejecutiva, solo se logra al adoptarse alguna de las medidas conservativas que el ordenamiento franquea; no bastando para ello la pura declaración del juez. Ahora bien, gran parte de la doctrina sostiene que estas medidas son accesorias al embargo, y que su inexistencia no acarrea su ineficacia.

Nosotros, en cambio, creemos que sin las medidas conservativas el embargo se torna inútil y estéril. Sin ellas no puede producir efecto alguno. Sobre este punto versará nuestro trabajo, centrándonos en el embargo sobre bienes inmuebles o derechos reales constituidos sobre ellos.

\section{ANTECEDENTES HISTÓRICOS DEL PROCEDIMIENTO DEL EMBARGO (CON ESPECIAL ÉNFASIS EN LAS MEDIDAS CONSERVATIVAS)}

Para un mejor acercamiento al tema, en este capítulo haremos una breve reseña acerca de los antecedentes históricos del embargo en nuestro país. Para ello analizaremos sus raíces castellanas, luego su reglamentación en la ley Mariana de 1837, para finalizar con el proceso de codificación y la promulgación del Código.

En primer lugar nos dedicaremos a estudiar el procedimiento de embargo y luego el desarrollo que han tenido las medidas conservativas.

\subsection{El PROCEDIMIENTO DE EMBARGO}

\subsubsection{En Castilla}

Las Partidas normaban el proceso ejecutivo en forma muy escueta, dedicándole tan solo seis leyes (contenidas bajo el Título XXVII de la Partida III). Tratándose del procedimiento de embargo, su regulación también era muy sucinta. La ley II, ordenaba que en primer lugar debía aspirarse al cumplimiento voluntario de la sentencia. Solo la oposición del deudor, esto es el rechazo a entregar la cosa debida, daba pie a la ejecución forzosa mediante el uso de la fuerza y de hombres armados.

En la Nueva Recopilación la regulación era más extensa. Seleccionados los bienes que debían ser ejecutado, sean muebles o raíces, se debían secuestrar, inventariar y depositar en persona abonada ${ }^{1}$. Por regla general, la ejecución podía recaer en cualquier bien, a excepción -dice Hevia Bolaños- en las cosas sagradas y destinadas al culto divino, en las Capillas y Sepulturas del deudor ${ }^{2}$. Tampoco se pueden embargar las naves "del Reino que trajeren mantenimiento ó mercaderías á él", ni en las armas, en los libros de los Estudiantes, Letrados y Abogados; en los bueyes ni otros animales, en arados, aperos ni aparejos de arar, ni en los esclavos, tampoco en el estipendio de los soldados y personas militares; ni en el estipendio de "los Militares celestes, que es el que tienen los Sacerdotes de sus beneficios"; en la cama, vestido ordinario y otras cosas necesarias para el

\footnotetext{
${ }^{1}$ HeVia Bolaños (1853) p. 142.

${ }^{2}$ Hevia Bolaños (1853) pp. 143 y 144.
} 
uso cotidiano de cualquier persona; tampoco en el derecho a recibir alimentos "porque no se puede ceder, ni renunciar" 3 .

\subsubsection{En la ley Mariana de 1837}

En su artículo 20, se regulaba el trámite del embargo. Decía que las partes podían presenciarlo, por sí o a través de sus apoderados, y cuya diligencia podrán firmar si supieren; en caso contrario, o que no sepan, se hará mención de ello. Luego, el artículo 28 señalaba que "[h] echa la traba, se le notificará al deudor si no la hubiere presenciado, y al mismo tiempo se le citará a remate", luego de lo cual tendrá dos días naturales ${ }^{4}$ para pagar la deuda u oponerse a la ejecución, "siéndole permitido para proponer sus exepciones examinar el proceso sin sacarlo de la oficina donde estuviere".

En el artículo 18, se señalaban los bienes inembargables, incluidos en siete numerales, todos los cuales se encuentran comprendidos en el actual artículo 464 CPC, a excepción de su último número, que decía relación con la inembargabilidad de "[l]os frutos rurales antes de recolectarse".

Por su parte, el artículo 21 recogía la institución denominada "la ampliación del embargo", para el caso que el acreedor entendiese que no son suficientes los bienes trabados, o que se han dejado de embargar otros por haberse ocultado.

\subsubsection{El Proyecto de 1861}

En 1861 fue publicado el "Proyecto de Código de Enjuiciamiento Civil para la República de Chile" 5 . Este primer proyecto, que corresponde al de Florentino González, jurista y magistrado colombiano, destaca por la detallada y exhaustiva regulación del procedimiento de embargo, por lo que hemos decidido tratarlo en forma separada al resto.

En el Libro VI del proyecto, que regulaba el juicio ejecutivo, el embargo es tratado en varios títulos. El Título VIII trataba del "Embargo suspensivo"; el Título IX "Del embargo ejecutivo de bienes muebles"; el Título X "Del embargo de frutos no cosechados"; el Título XI "Del embargo de rentas constituidas sobre particulares"; y finalmente el Título XIII acerca "Del embargo de bienes inmuebles".

En el título dedicado al embargo suspensivo, se regulaba la situación del acreedor que se encontraba en el caso de que los bienes o valores pertenecientes a su deudor estuvieran en poder de un tercero. Se distinguía para tales efectos si el acreedor era o no portador de un título ejecutivo. En el primero caso, disponía el artículo 737 que "[t]odo acreedor portador de un título ejecutivo puede solicitar de cualquier juez que embargue entre las manos de un tercero las sumas o valores pertenecientes a su deudor; i el juez, en vista del título deberá decretar sin demora el embargo, i llevarla a efecto". Para el segundo, en el que el acreedor carece de título, podía solicitar el embargo jurando que

\footnotetext{
${ }^{3}$ HeVia Bolaños (1853) pp. 143 a 146.

${ }^{4}$ LIRA (1868) t. III, p. 72 (n. h), señala que la expresión dos días naturales, debía entenderse como equivalente a 48 horas, y por ello se acostumbraba a poner en las diligencias la hora en la que era practicada. Sin embargo, el autor señala que con la promulgación del Código Civil el término debía contarse conforme las reglas del artículo 48 del citado cuerpo legal.

${ }^{5}$ En Santiago, Imprenta Nacional.
} 
los bienes que están en poder del tercero pertenecen a su deudor. Luego, el ejecutante debía poner en conocimiento de su deudor el embargo efectuado, interponiendo una demanda para que se declare válido el embargo.

El Título IX estaba dedicado al embargo ejecutivo de bienes muebles. El artículo 767 decía que el juez o el oficial de justicia que realice el embargo, debía ser acompañado por dos testigos ${ }^{6}$. Posteriormente debía levantarse un acta firmada por el juez y estos, dejándose constancia en caso que estos últimos no quisieran hacerlo o no supieran (art. 768). Dispone el artículo 769 que “[e]l acreedor no podrá hallarse presente a la diligencia de embargo".

Si el embargo se hacía en el domicilio del deudor, "se procederá a embargar todas las cosas de su pertenencia que se hallen en él, menos las que se exceptúan por disposiciones de artículos posteriores de este título"7.

En la diligencia de embargo debía contenerse una designación detallada de los objetos, y si eran mercancías, estas debían ser pesadas o medidas (art. 784).

En el Título X se regulaba la figura del embargo de los frutos no cosechados, esto es, de los frutos pendientes del terreno, que "no podrá hacerse sino en las seis semanas que preceden a la época ordinaria de la madurez de los frutos" (art. 830). La diligencia del embargo debía contener "la indicación de cada clase de frutos, la extensión de la plantacion, i el nombre de los colindantes” (art. 832).

El Título XI regulaba la figura del embargo de rentas constituidas sobre particulares. Según lo dispone el artículo 841, este era "el embargo de una renta o censo constituido a perpetuidad o temporalmente, mediante un capital entregado a una persona, o por precio de la venta de un inmueble, o por cualquier otro título oneroso, o gratuito, no podrá hacerse sino en virtud de título ejecutorio, i por un mandamiento de juez competente...". La adjudicación de la renta o censo se hacía conforme las reglas establecidas para los inmuebles (art. 855).

Finalmente, el Título XIII estaba dedicado al embargo de bienes inmuebles que -de conformidad con el artículo 882- debía hacerse "en virtud de un mandamiento del juez en que se ordene el embargo por falta de pago".

La diligencia de embargo debía constar en un acta que debía contener: "10 enunciación del título ejecutorio en virtud del cual se procede contra bienes del deudor. $2^{\circ}$ mención del transporte del juez u oficial de justicia ejecutor al lugar en donde están situados los bienes inmuebles. $3^{\circ}$ designación de estos bienes; a saber, si es una casa, la calle de la aldea, villa o ciudad, i el departamento en que se halle situada, i el nombre de los propietarios de las dos casas vecinas; si es un fundo rural, la designación de los edificios, cuando los haya, la naturaleza i contenido aproximativo de cada pieza, el nombre de los arrendatarios o colonos, si los hai, i el departamento en donde están situados los bienes. $4^{\circ}$ indicación del juez que conoce del embargo, i domicilio del acreedor" (art. 886).

\footnotetext{
${ }^{6}$ No podían serlo los parientes del juez o de las partes dentro del cuarto grado de consanguinidad o segundo de afinidad, ni sus sirvientes domésticos.

${ }^{7}$ A su turno, el artículo 777 dice que "[n]o podrán ser embargados los objetos esceptuados de embargo por el artículo 1618 del Código Civil”.
} 
El embargo, "se notificará al deudor dentro de los quince dias siguientes al de la terminacion de la diligencia" (art. 887). Otra copia, lo dispone el artículo 888, "se entregará dentro de los mismos quince dias al acreedor, para que la haga transcribir en el rejistro del conservador del departamento en donde estén situados los bienes y otra copia debía ser entregada al acreedor, para que procediera a transcribir en el conservador respectivo el embargo".

Asimismo, el artículo 892 permite para el caso de que "los inmuebles no están alquilados o arrendados, el propietario deudor quedará en posesión de ellos hasta la venta,...".

El embargo se entendía efectuado no solo sobre el terreno, sino sobre todo lo que se encuentra en él. Así se desprende de los artículos $893^{8}$, $894^{9}$ y $895^{10}$.

\subsubsection{En los demás proyectos}

En 1867 fue publicado el Proyecto de Código de Enjuiciamiento Civil de don Francisco Vargas Fontecilla ${ }^{11}$, que solo contaba con un Libro I, relativo a las disposiciones comunes a todos los juicios.

Posteriormente, en 1870 se encomendó a don Joaquín Blest Gana la continuación del trabajo inconcluso de Vargas Fontecilla. De este modo, el año 1872 fue publicado su proyecto relativo al Libro III, sobre juicios especiales, con 233 artículos no numerados ${ }^{12}$.

En el proyecto sobre juicio ejecutivo de Blest Gana, el procedimiento de embargo tuvo un tratamiento escueto; señalando en su artículo decimoquinto que“[v] erificado el embargo, los bienes se pondrán a disposición del depositario que el acreedor designe bajo su responsabilidad... Si los bienes embargados se encontraren en diversos departamentos, o consistieren en especies de distinta naturaleza, puede nombrarse mas de un depositario".

En 1884 fue publicado el libro "Proyecto de Código de Enjuiciamiento Civil. Conforme los acuerdos hasta ahora celebrados por la comisión encargada de su examen"13. Advertía que una vez practicada la diligencia del embargo, el ministro de fe levantará un acta con la expresión individual y detallada de los bienes afectados, quien deberá firmarla, conjuntamente con el depositario, y por el acreedor y deudor si concurren. Si alguna de las partes no quisiere firmar, se hará mención de ello (art. 427). Advertía el artículo 432 que "[v]erificado el embargo, el ministro ejecutor entregará inmediatamente la dilijencia en la secretaría; i el secretario pondrá constancia del dia en que la recibe".

${ }^{8}$ Dice el artículo "[p]odrá procederse inmediatamente a cosechar i vender los frutos que estén en estado de madurez, observándose lo dispuesto en el título respectivo de este libro sobre la venta de frutos embargados, i el precio se conservará en deposito hasta que se ordene el pago".

${ }^{9}$ La disposición ordena que "[l] os productos naturales e industriales recojidos después de la trascricion de la diligencia de embargo, o el precio que provenga de ellos, serán inmobilizados para ser distribuidos con el precio de los inmuebles, por órden de hipotecas".

${ }^{10} \mathrm{La}$ norma indica que "[e]l propietario del fundo embargado no podrá hacer ningun corte de maderas, ni desmejora alguna, bajo pena de pagar daños i perjuicios, i de ser perseguido criminalmente,...”.

${ }^{11}$ En Santiago, Imprenta Nacional.

12 Proyecto de Código de Enjuiciamiento, Santiago, Imprenta de La República, 1872.

${ }^{13}$ En Santiago, Imprenta "El Progreso". 
El proyecto expresamente reguló la figura de la ampliación del embargo. Reconocía la facultad del acreedor de pedirla en cualquier estado del juicio, si existía justo motivo para temer que los bienes no alcancen a cubrir la deuda y costas. Era justo motivo el hecho que la traba recaiga sobre bienes de difícil realización. También la introducción de cualquier tercería sobre los bienes embargados.

Así como el acreedor podía solicitar la ampliación del embargo, el deudor podía hacerlo cesar, consignando cantidad suficiente para el pago de la deuda y las costas.

Luego de sucesivas revisiones al proyecto del año 1884, se publicó el Proyecto de Código de Procedimiento Civil de $1893^{14}$. En su artículo 470 establecía que el embargo se entenderá "hecho por la entrega real o simbólica de los bienes al depositario que se designe, aunque este deje la especie en poder del mismo deudor".

En su artículo 475 establecía que cuando la cosa embargada se halle en poder de un tercero que se oponga a su entrega alegando el derecho de gozarla a otro título que el de dueño, "no se hará alteración en este goce hasta el momento de la enajenación, ejerciendo mientras tanto el depositario sobre la cosa los mismos derechos que ejercia el deudor”.

Finalmente, el proyecto establecía que verificado el embargo el ministro de fe entregará inmediatamente copia de la diligencia en secretaría y el secretario dejará testimonio del día en que la recibe (art. 476), estableciéndose, además, la facultad de solicitar la ampliación del embargo en términos similares al proyecto de 1884 y la posibilidad de que el deudor haga cesar la traba consignado cantidad suficiente para el pago de la deuda y costa.

\subsubsection{En el Código de Procedimiento Civil}

El procedimiento de embargo se encuentra establecido en los artículos 447 y siguientes del código. A diferencia del artículo 16 de la Ley Mariana sobre juicio ejecutivo, se permite concurrir primeramente al acreedor para que designe bienes, con tal que no excedan de los necesarios para responder de la demanda. Según el artículo 450 el embargo se entiende hecho con la entrega real o simbólica de los bienes al depositario, aunque estos se dejen en poder del mismo deudor. Este último artículo parece establecer una regla similar a la contenida en el artículo 6 No 1 de la antes mencionada ley Mariana, que decía que las cosas embargadas deben depositarse "en persona de reconocida responsabilidad, dejando trabada en ellos la ejecución”.

El código termina regulando detalladamente las menciones que debe contener el acta de embargo, ordenando que sea firmada por el ministro de fe que practique la diligencia y por el depositario, acreedor o deudor que concurran al acto si así lo desean. Finalmente ordena dejar constancia de toda alegación que haga un tercero invocando la calidad de dueño o poseedor del bien embargado.

14 Estamos utilizando el Proyecto de Código de Procedimiento Civil revisado por la Comisión Mista de Senadores i Diputados, Imp. Litografía i Encuadernación Barcelona, Santiago, 1902. 


\subsection{LAS MEDIDAS CONSERVATIVAS EN LOS PROYECTOS DEL CÓdigO DE PROCEDIMIENTO CiVIL}

En la Nueva Recopilación, seleccionados los bienes, estos eran secuestrados, inventariados y depositados en persona abonada para el desempeño del cargo. La figura del depositario sería una institución que comenzaría a encontrarse en toda la futura legislación ejecutiva. En efecto, ya en el artículo 6 No 1 de la ley Mariana de 1837 se ordenaba que los bienes embargados debían ser depositados en persona de reconocida responsabilidad; situación que se mantuvo en los proyectos del Código de Procedimiento Civil.

En el proyecto redactado por Florentino González, la figura del depositario era regulada en los artículos 784 y siguientes. Conforme la norma mencionada " $[\mathrm{s}] \mathrm{i}$ el deudor ofrece una persona solvente que se encargue voluntariamente del depósito de los bienes embargados, se hará en ella el nombramiento de depositario, i se le entregarán los bienes para su custodia"; en caso contrario, dice el artículo 785, "el juez hará el nombramiento de un depositario". A su turno, el artículo 788 decía que los bienes serán entregados al depositario "con una copia de la diligencia de embargo en que esten enumerados, la cual copia se dejará en su poder; i se extenderá una diligencia en que conste la entrega,...”. Finalmente reseñaba que el depositario no podía servirse de las cosas entregadas en custodia, ni alquilarlas o prestarlas, bajo pena de perder sus honorarios y pagar los daños (art. 793) y, si producían algún producto o renta, debía dar cuenta de ello (art. 794).

Tratándose del embargo de frutos no cosechados, el proyecto de González ordenaba al juez ejecutor nombrar "un guardia depositario, que tendrá el deber de cuidar que la plantacion no sufra daño ni menoscabo" (art. 833); y para el caso del embargo de rentas constituidas sobre particulares "el embargo se hará ordenando al que debe la renta la retención en sus manos” (art. 843).

En la misma línea, aunque ciertamente en forma mucho más sucinta, el proyecto sobre juicio ejecutivo de Blest Gana reconocía la figura del depositario. Este proyecto ordenaba -en su artículo décimoquinto- que una vez verificado el embargo los bienes debían ser entregados al depositario que el acreedor designe.

Posteriormente, en el proyecto del año 1884, heredero de la Ley Mariana sobre juicio ejecutivo, se mandaba que, practicada la diligencia de embargo, los bienes debían ponerse a disposición del depositario, que el acreedor designe bajo su responsabilidad. En caso de que el acreedor no lo haga, el depositario será nombrado por el ministro de fe. Si los bienes embargados se encontraban en diversos departamentos o consistieren en especies de diversa naturaleza, podía nombrarse más de un depositario; y si los bienes embargados fueren dineros, alhajas, especies preciosas o efectos públicos el depósito se hará en un banco, en su defecto, en arcas fiscales o en poder de una persona que el tribunal designe (art. 428). El proyecto de 1884 terminaba señalando que la administración de los bienes embargados correspondía al depositario, quien tratándose de especies muebles, podía trasladarlos al lugar que creyere más conveniente, salvo que el deudor afiance su conservación (art. 456).

El proyecto de 1893 conservó el mismo plan que su antecesor. En su artículo 471 contenía una disposición equivalente al artículo 428 del proyecto inmediatamente ante- 
rior. Con todo, su artículo 470 prescribía que el embargo se entenderá "hecho por la entrega real o simbólica de los bienes al depositario que se designe, aunque este deje la especie en poder del mismo deudor"

Finalmente, el CPC en su artículo 450, inc. $1^{\circ}$, mantuvo la misma orientación que se vislumbraba en el artículo 6 No 1 de la ley Mariana sobre juicio ejecutivo y en el artículo 470 del proyecto de 1893, advirtiendo que el embargo se entiende hecho por la entrega real o simbólica de los bienes al depositario.

A diferencia de la figura del depositario, que aparece en los albores de la legislación procesal, la anotación registral del embargo de inmuebles fue una cuestión ignorada en nuestro ordenamiento hasta la publicación del proyecto de González.

Este autor tuvo presente dicha omisión, y en su proyecto incluyó esta medida conservativa de la traba, expresando que para ello tuvo a la vista la legislación francesa de la época (el edicto de 1771, la ley 11 de brumario del año VII y especialmente la ley de 2 de junio de 1841); ordenamiento que le sirvió de guía para redactar las disposiciones sobre embargo y venta de los bienes muebles y especialmente sobre transcripción del embargo en el registro conservatorio respectivo ${ }^{15}$. Es a propósito de esta cuestión que el autor hace un velado reproche a la legislación española, que tan fuertemente se advertía en nuestro ordenamiento, al señalar: "[1] a trascricion de la dilijencia de embargo en el regjistro del conservador... [es una] precaución, en que no pensaron nunca los lejisladores españoles"16.

En el Libro VI, Título XIII, del proyecto de González, se regulaba la traba de bienes raíces, cuya diligencia debía constar en un acta con las menciones señaladas en el artículo 886. Copia de dicha acta, según lo disponía el artículo 888, debía ser entregado dentro de los quince días siguientes al acreedor, para proceder a su transcripción en el registro del conservador correspondiente. Indicaba el artículo 892 que para el caso de que "los inmuebles no están alquilados o arrendados, el propietario deudor quedará en posesión de ellos hasta la venta,...”.

La inscripción tenía dos funciones. La primera, establecida en el artículo 891, en el sentido de que "el conservador rehusará transcribir la copia que se le presente, i hará constar al pié de ella su denegación, la fecha del embargo anterior, los nombres i domicilio del acreedor que lo haya hecho, i del deudor, el juez que conoce del embargo, i la fecha de la trascricion de la diligencia”. La segunda, contenida en el artículo 900, que instauraba la prohibición para el deudor de "enajenar los inmuebles embargados después que se haya transcrito en el rejistro del conservador la diligencia de embargo, bajo pena de nulidad de la enajenación, sin que haya necesidad de hacerla declarar"; pero -dice el artículo 901- será válida la enajenación "si el comprador de la finca consigna, ántes del dia señalado para la adjudicación, la suma bastante para pagar a los acreedores inscritos el monto de sus créditos, i los intereses i gastos”.

El proyecto de 1884 no se distingue sustancialmente del anterior, indicando en su artículo 431 que el embargo sobre bienes raíces, o sobre derechos reales constituidos 
sobre ellos ${ }^{17}$ debía inscribirse en el registro conservatorio del departamento en que el inmueble se encuentre situado ${ }^{18}$.

Por último, el proyecto de 1893 mantuvo en su esencia la anotación registral de que venimos hablando, pero en su artículo 474 dejó claramente establecido que la inscripción no produciría efecto respecto de terceros sino que desde la fecha en se inscriba en el registro conservatorio respectivo.

El Código de Procedimiento Civil, en su artículo 453 establece que el embargo sobre bienes raíces o sobre los derechos reales constituidos sobre ellos no produce efecto respecto de terceros desde su inscripción marginal en el registro conservatorio. Esta disposición vino a modificar el artículo 53 No 3 del Reglamento del Registro Conservatorio de Bienes Raíces que indicaba que era facultativo la inscripción del embargo. Asimismo vino a establecer un requisito especial para la declaración de la nulidad absoluta establecida en el artículo 1464 No 3 del Código Civil, prescribiendo que para su declaración el embargo debe encontrarse inscrito.

De la descripción referida, parece desprenderse que el depositario era originalmente una medida conservativa establecida para el embargo de bienes muebles como de bienes raíces. Las disposiciones mencionadas no distinguen entre unos y otros. Y no parece del todo ilógico la existencia de este figura para el caso del embargo de bienes raíces a los que se encuentran adheridos en forma permanente otros inmuebles.

17 La expresión "o sobre derechos reales constituidos en ellos" fue agregada a petición del comisionado Gandarillas, sin expresar su fuente. Sesión No 26 de 17 de diciembre de 1875, en "Actas de la Comisión Revisora del Proyecto de Enjuiciamiento Civil".

18 Según señala, Allende (1897) pp. 26-29, que el Senado de la República, en sesión de 19 de julio de 1886, aprobó una modificación del artículo 1464 del Código Civil en los siguientes términos: "Artículo único: agréganse al art. 1464 del Código Civil los siguientes incisos:

'50 De las cosas cuya enajenacion estuviese prohibida por decreto judicial, a ménos que el juez o el acreedor consienta en ello.

'El embargo, lítis o prohibicion de enajenar a que se refieren los números $3^{\circ}, 4^{\circ}$ y $5^{\circ}$ se inscribirán en el Rejistro del Conservador de Bienes Raices del departamento o departamentos a que por su situación pertenezca el inmueble.

'La inscripcion se hará dentro del plazo prudencial que en cada caso deberá fijarse por el juez que conoce de la causa. Las que se hicieren despues de transcurrido dicho plazo solo podrán causar accion de nulidad desde la fecha de sus respectivas anotaciones en los rejistros correspondientes.

'Los embargos, lítis o prohibiciones de enajenar inmuebles anteriores a la vijencia de esta lei, deberán inscribirse en el Rejistro Conservatorio correspondiente en el término de cuarenta dias contados desde su promulgacion.

'Espirado este plazo, solo producirán nulidad respecto de terceros las enajenaciones que se hiciesen desde la fecha de la inscripcion".

El proyecto, aprobado con caracteres de urgente, paso a la Cámara de Diputados de la cual nunca más salió.

El autor observa la necesidad de legislar rápidamente sobre este tema, sin embargo advierte que puede suceder que los terceros de buena fe que hayan contratado con el deudor entre el tiempo que media entre la fecha del embargo, litis o prohibición y la fecha de la respectiva inscripción, resulten perjudicados; del mismo modo que los terceros de mala fe, podrán contratar válidamente sobre los inmuebles embargados, litigiosos o respecto de los cuales su enajenación se encuentre prohibida, siempre que por cualquier motivo se retarde la inscripción. 
En relación con la oponibilidad del embargo, el artículo 450 establece que este se entenderá hecho -tanto para las partes como para terceros- desde la entrega real o simbólica de las cosas al depositario. Pero luego advierte, en el artículo 453, que tratándose del embargo de bienes raíces o de derechos reales constituidos en ellos, este se entenderá hecho respecto de terceros solo desde su anotación en el respectivo registro conservatorio.

\section{SíNTESIS DE LA PROBLEMÁTICA QUE SE PLANTEA}

Como adelantamos, nos proponemos estudiar una cuestión que se relaciona directamente con la estructura del embargo, concebida como el acto o conjunto de actos que, según el ordenamiento jurídico, lo integran y que, por tanto, originan los efectos jurídicos que el derecho le atribuye ${ }^{19}$. Esta cuestión se refiere a si las medidas conservativas son o no parte integrante de la estructura del embargo; cuestión nada fácil ni pacífica.

Para algunos, el embargo esta constituido única y exclusivamente por la "declaración jurisdiccional de afectación de unos determinados bienes del ejecutado a la ejecución” 20 .

Para otros, si bien "suele ser una actividad muy compleja... [el] [p]resupuesto necesario de la ejecución es solo el acto judicial de afectación o traba" ${ }^{21}$. Para estos, el embargo es una actividad que conlleva una serie de hechos de naturaleza selectiva y volitiva conformada por una pluralidad de actos, en que se presentan una serie de actuaciones, declaraciones de voluntad y de conocimiento, hechos del juez, de las partes o de terceros, sean o no titulares de una función pública ${ }^{22}$. Esta corriente sostiene que, si bien el embargo es una actividad compleja, tiene un núcleo central, consistente en la declaración de voluntad jurisdiccional mediante el cual se afecta un determinado bien a la ejecución ${ }^{23}$.

Sea cual sea la posición adoptada, todos estos autores coinciden en que las medidas conservativas de la traba son accidentales al embargo. A consecuencia de lo anterior, ambas posiciones desechan el carácter constitutivo de las medidas asegurativas, de modo que el embargo puede existir, aun cuando dichas prevenciones no hayan sido adoptadas 24 .

\footnotetext{
19 CACHÓN (1991) p. 40.

${ }^{20}$ CACHÓN (1991) p. 61.

${ }^{21}$ FERNÁNDEZ et al. (1995) t. V, p. 321. Para el autor, la traba o afección es "una declaración de voluntad del Juez ejecutor por la que traba uno o varios bienes determinados de entre los que forman el patrimonio del deudor, con la finalidad de proyectar sobre ellos los actos ejecutivos posteriores", FERNÁNDEZ et al. FRANCISCO (1995) t. V, p. 344.

22 Carreras (1957) p. 99. En nuestro país, NAVArRete (2004) p. 48.

23 CARRERAS (1957) pp. 130-131. NAVARRETE (2004) p. 67.

${ }^{24}$ CACHÓn (1991) p. 61. En igual sentido, FERnÁndeZ et al. (1995) t. V, p. 321; CARReras (1957) pp. 130 y 131, advierte que "[l]as demás actividades que puedan llevar a cabo el Juez ejecutor [y que no consista en su declaración de tener por afectado determinado bien], y las que puedan realizar los demás sujetos del proceso, no son necesarias para que el embargo exista".
} 
Para esta doctrina, claramente mayoritaria, el embargo es el medio por el que se determinan los bienes que, dentro del patrimonio del deudor, van a responder de una ejecución concreta, de modo que es eficaz y cumple su finalidad con la pura declaración jurisdiccional tendiente a seleccionar bienes y establecer cuáles serán trabados, sustituyendo el juez ejecutor al responsable en una obligación jurídica que se niega a realizar.

Es en este sentido que Navarrete dice que el embargo existe y es válido con la sola declaración de voluntad del juez con la que declara afectado un determinado bien a la ejecución ${ }^{25}$. Así, las medidas conservativas "conforman la última fase del embargo, integran la actividad total, pero no son el embargo mismo, y por ello la norma puede decir con cierta corrección que el embargo se entenderá hecho por la entrega real y simbólica de los bienes al depositario etc. (artículo 450 Código de Procedimiento Civil), lo que indica prioridad de la declaración de voluntad (afección o traba) sobre la garantía posterior, y que la última etapa es la garantía de la traba. O que el embargo de bienes inmuebles se deberá inscribir en el respectivo registro conservatorio para que produzca efecto legal respecto de terceros (artículo 453 Código de Procedimiento Civil), denotando claramente que el embargo es anterior en el tiempo a la anotación registral; la garantía registral es una fase del embargo, pero no el embargo mismo"26.

El análisis propuesto por Navarrete concluye que es posible distinguir la traba de las medidas conservativas, ambas situaciones tienen finalidades diversas y tienen lugar en momentos distintos y que, siendo la traba el núcleo central del embargo, este puede existir sin que se hayan adoptado sus garantías.

Por nuestra parte, y como pasaremos a exponer, estimamos que la medida de la anotación registral es indispensables para que el embargo pueda cumplir con uno de sus fines, el de otorgar seguridad al acreedor de que la ejecución llegará a buen recaudo. Cuestión que, por lo demás, tiene importantes consecuencias prácticas tratándose del embargo que dicha medida garantiza.

\section{DE LOS EFECTOS DEL EMBARGO}

\subsection{ACERCA DE LA FINALIDAD EJECUTIVA DEL EMBARGO}

La finalidad ejecutiva del embargo se deriva de que dicha institución se inserta en un proceso de ejecución, encontrándose ligada estrechamente a la realización forzosa. El embargo es la vía idónea y excluyente a través del cual se seleccionan bienes del patrimonio del deudor para su ulterior venta ${ }^{27}$. De este modo, el embargo es el único medio para determinar qué bienes, de aquellos que forman parte del patrimonio del ejecutado, van a responder de una ejecución concreta, por lo que, sin esa afectación previa, la realización es derechamente imposible.

\footnotetext{
25 NAVARRETE (2004) p. 72.

${ }^{26}$ NAVARrete (2004) p. 71. En similar sentido CARreras (1957) p. 129.

27 Serra Domínguez (1969) p. 530. En este sentido, Prieto Castro et al. (1983) v. 2o, p. 180, el embargo es un acto por el cual "se declaran y quedan adscritos a la satisfacción del crédito del acreedor" los bienes y derechos del deudor.
} 
En otros términos, a través del embargo es posible lógica y jurídicamente la actividad ejecutiva posterior: la realización de los bienes. Señala Carreras que solo por medio de la traba es lógicamente posible la realización; no puede existir realización sin embargo. Pero también solo a través del embargo es jurídicamente viable la realización, al permitir controlar la pertenencia de los derechos afectados al ejecutado, únicos que pueden ser realizados ${ }^{28}$.

De este modo, el carácter ejecutivo del embargo deriva de que su finalidad es hacer posible, sobre bienes concretos, la ejecución actual de una responsabilidad cierta, sin el cual resulta inverosímil cualquier acto de realización ${ }^{29}$. El embargo cumple la labor de presupuesto esencial para la validez de las actuaciones ejecutivas. En el evento que no haya tenido lugar o se haya efectuado en forma irregular, los actos ejecutivos posteriores serán ineficaces ${ }^{30}$.

La finalidad ejecutiva de la traba, que permite se concrete el objeto del apremio, también garantiza al deudor la seguridad de que su patrimonio se encuentre a buen recaudo. En efecto, si bien para el ejecutante el embargo le permite determinar los derechos que serán realizados, al deudor le otorga y garantiza la tranquilidad de que la totalidad de su patrimonio ha dejado de encontrarse amenazado por un eventual apremio $^{31}$. A través de la afección ejecutiva, la responsabilidad general del deudor, contenida en el artículo 2465 del CC, se cristaliza en bienes concretos, de modo que los demás que integran su patrimonio quedan al margen de la ejecución (siempre que los derechos primeramente trabados sean suficientes para el pago de lo adeudado).

Además, el carácter ejecutivo de la afección beneficia a los terceros ajenos al proceso de ejecución, y que pueden verse envueltos en él. El hecho que la traba sea indispensable para proceder a la realización de los bienes, determinando los que concretamente deberán ser objeto de ella, permite a los terceros, en el tiempo intermedio entre la afección y la venta forzada, evitar el perjuicio que se cierne sobre sus bienes que se han visto afectados por un embargo ${ }^{32}$.

\subsection{SOBRE LA FINALIDAD CONSERVATIVA DEL EMBARGO}

La doctrina española estima que el embargo se agota en una declaración jurisdiccional de afección ${ }^{33}$.

La exclusión de la finalidad conservativa se explica porque en ese ordenamiento la traba no impide la transferencia de un bien a un tercero. El embargo asegura y garantiza

\footnotetext{
28 CARRERAS (1957) pp. 98 y 99. En nuestro país, TAVOlARI (2000) p. 171, advierte que “[p]ara comprender el tema es indispensable reparar que, aunque nosotros mismos hayamos estimado que el embargo comparte caracteres cautelares con ejecutivos, es lo cierto que, principal, esencialmente, se trata de un instituto ejecutivo. Él constituye el antecedente jurídico necesario para que opere una consecuencia jurídica específica: la enajenación forzada”.

29 FERNÁNDEZ et al. (1995) t. V, pp. 320 y 321.

${ }^{30}$ NAVARRETE (2004) p. 58.

31 CACHÓN (1991) p. 36.

32 CACHÓN (1991) p. 36.

33 Entre otros, Carreras (1957) pp. 101-103; CACHÓn (1991) pp. 38 y 39.
} 
que la afección no desaparecerá aunque se haya dispuesto del bien. Como bien señala un autor español "la traba no expropia el derecho de disposición de los bienes embargados. El deudor ejecutado puede disponer y enajenar válidamente los bienes inmuebles que han sido embargados" 34 .

Por nuestra parte sostenemos que en nuestro ordenamiento, el embargo sí impide disponer de los derechos trabados en una ejecución. Para el caso que ello ocurra, la sanción de ineficacia que establece el derecho es la más grave: la nulidad absoluta (artículo 1464 No 3 y 1578 No 3, ambos del CC). Tan claro resulta que el ejecutado ha sido desprovisto de su facultad de disposición ${ }^{35}$ que, tratándose de la enajenación de derechos reales constituidos sobre bienes inmuebles, la escritura de compraventa debe ser firmada por el adjudicatario y el juez, como representante legal del vendedor (art. 497 del CPC).

De este modo, mediante el embargo se retienen los bienes en el patrimonio del responsable, para posteriormente dirigir en su contra toda la actividad ejecutiva ${ }^{36}$. El embargo se constituye en una verdadera medida de garantía, porque su finalidad es asegurar la eficacia de la función jurisdiccional, poniendo a disposición del ejecutor todos los elementos que le permitan en la oportunidad que corresponda hacer justicia.

A través del embargo se ordena al deudor abstenerse de realizar cualquier acto dirigido a restar como garantía del crédito los bienes que se someten a la ejecución, de modo que "éste inicia la sujeción del bien a la concreta acción ejecutiva". El embargo tiene por finalidad no solo individualizar el bien sobre el cual el ejecutor deberá proceder para satisfacer al acreedor, sino que además lo somete materialmente a la transferencia coactiva, impidiendo que ese vínculo desaparezca ${ }^{37}$.

Atendido que el embargo permite asegurar los fines de la ejecución forzosa, muchos autores lo han calificado con una verdadera medida precautoria ${ }^{38}$. El hecho que el embargo comparta uno de sus fines con las medidas precautorias, específicamente con la retención ${ }^{39}$, no permite concluir que ambas participen de una misma naturaleza. No

\footnotetext{
34 FERNÁNDEZ et al. (1995) t. V, p. 351, quienes además advierten que "lo mismo cabe decir por analogía, respecto de los bienes muebles embargados: su titular conserva la facultad de disposición, pero no libre, sino con la carga que el embargo supone". Veáse, CACHÓN (1991) pp. 73 y ss. y CORDÓn MORENO (2002) pp. 293 y ss.

35 Pinto con Rebolledo (1945): "El embargo produce los siguientes efectos: sujeta al deudor a la medida precautoria de prohibición de enajenar los bienes embargados y de gravarlos de cualquier modo que signifique desmembrar o limitar el dominio; priva al deudor de la tenencia y administración de dichos bienes que pasan al depositario, y sujeta al deudor al procedimiento de apremio,...”. En similar línea, Banco de Chile (1995): "[q] ue el embargo es una actuación judicial que tiene por finalidad sustraer un bien del comercio humano,...".

36 BenAVENTE (1961) p. 94; Riveros (1964) pp. 18 y 21. En similar sentido, Jiménez (1956) p. 7; VIERA, (1949) p. 49.

${ }^{37}$ Micheli (1970) t. III, pp. 154 y 155.

38 EspinOSA (2003) pp. 142 y 143, LiLlo (sin año) p. 82. También, CASARino (2007) p. 67, para quien si bien el embargo de bienes habilita al acreedor para realizarlos y pagarse con el producto, "[e]n cierto aspecto, participa también de la característica de las medidas precautorias, puesto que tiende a asegurar el resultado de la acción ejecutiva interpuesta por el acreedor;...”.

39 Véase al efecto, MARín (2004) pp. 391 y ss.
} 
siendo tema de este trabajo, nos quedamos con las palabras de Pereira Anabalón quien a este respecto señala que, si bien es "nula por ilicitud del objeto la enajenación de las cosas que han sido embargadas ejecutivamente y aquellas que han sido objeto de alguna de las precautorias mencionadas, con lo que existe identidad, solo para los señalados fines, entre embargo y precautoria. Lo que no significa que entre ambos exista identidad de naturaleza, puesto que, por el contrario, se ha establecido que la finalidad de la actividad jurisdiccional cautelar es diversa de la actividad jurisdiccional ejecutiva. Aquella, tiene por objeto la declaración de certeza de la posibilidad o de la probabilidad de un daño; esta, la realización coactiva del derecho declarado en la sentencia, a la que cabe añadir todo otro título al cual la ley asigne igual fuerza o mérito que la sentencia” ${ }^{0}$.

Ahora bien, es preciso señalar que las medidas conservativas del embargo muchas veces son insuficientes para asegurar al ejecutante que los bienes embargados se mantengan intactos hasta la ejecución.

Pensemos en un predio agrícola cuyo gran valor esta sujeto a la existencia de las plantaciones y sembrados que en él se encuentran. La anotación marginal del embargo podrá impedir que el terreno se transfiera pero en ningún caso podrá garantizar que lo que en él se encuentra exista al momento de la realización.

Esta cuestión, de gran importancia para lograr la completa satisfacción del crédito, ha sido considerada por la doctrina nacional. Y como solución frente a la insuficiencia de las medidas de garantía establecidas para el embargo se ha propuesto su convergencia con alguna medida precautoria. En este sentido Lillo Hunzinker no ve inconveniente alguno para que en el juicio ejecutivo puedan adoptarse todas las medidas precautorias que, de acuerdo a las reglas generales, son reconocidas en nuestro ordenamiento, incluso que pueda prepararse la ejecución a través de alguna medida prejudicial ${ }^{41}$.

A su turno, para Pereira Anabalón, es claro que el ordenamiento jurídico autoriza esta natural convergencia entre embargo y medidas precautorias, cuestión que se vería refrendada por lo dispuesto por el art., 444 inc. $1^{\circ}$ y $2^{\circ} \mathrm{CPC}$ al disponer que embargada la industria o sus utilidades, el depositario (medida ejecutiva) estará revestido de las calidades de interventor (medida cautelar) ${ }^{42}$.

\section{LAS MEDIDAS CONSERVATIVAS EN EL TEXTO LEGAL VIGENTE}

Sostenemos que el embargo tiene una finalidad conservativa, y que no puede agotarse en una mera declaración jurisdiccional tendiente a individualizar el bien sobre el mal él se desplegará toda la fuerza de la ejecución.

Esta aseveración se desprende del artículo 450, inc. 1º del Código que dice:

El embargo se entenderá hecho por la entrega real o simbólica de los bienes al depositario que se designe, aunque este deje la especie en poder del mismo deu-

\footnotetext{
40 PEREIRA (1993) p. 15.

${ }^{41}$ Lillo (sin año) p. 82. En este mismo sentido, ESPINOSA (2003) p. 142; QUEZADA (1997) p. 139.

42 Pereira (1993) pp. 23 y 24.
} 
dor. A falta de depositario designado por el juez, hará las veces de tal el propio deudor hasta tanto se designe un depositario distinto ${ }^{43}$.

El antecedente inmediato de la norma transcrita es el artículo 470 del proyecto de 1893, que establecía que el embargo se entenderá "hecho por la entrega real o simbólica de los bienes al depositario que se designe, aunque este deje la especie en poder del mismo deudor"; disposición que, en forma incipiente, ya se encontraba en el artículo 6 No 1 de la ley Mariana sobre juicio ejecutivo. Esta norma establecía que el mandamiento de ejecución debía ordenar que las cosas embargadas se depositen "en persona de reconocida responsabilidad, dejando trabada en ellos la ejecución”.

Que si bien el artículo 450, y sus antecedentes, se encuentran establecidos solo respecto de la traba de ciertos bienes, aquellos cuyo embargo es susceptible de ser garantizado con el depósito, establece un principio general en esta materia: el embargo se entiende hecho una vez adoptada la medida conservativa correspondiente, no bastando la mera declaración judicial. En este punto, se contiene una cuestión que ha sido muy discutida, que las medidas conservativas forman parte integrante del procedimiento de embargo.

Por lo demás, estimamos que los artículos 1464 No 3 y 1578 No 2, ambos del CC, establecen el mismo principio reconocido en el artículo 450, inc. $1^{\circ}$ CPC. En dichos artículos se sanciona con nulidad absoluta la enajenación de los bienes embargados por decreto judicial y el pago hecho al acreedor cuando el juez ha embargado la deuda o mandado retener lo debido. Esta sanción solo prosperará, según el CC, en el evento que los bienes hayan sido embargados, debiendo entenderse por tales aquellos que han sido objeto de la correspondiente declaración jurisdiccional y sobre los que se ha adoptado la pertinente medida conservativa. Si para el CC el embargo fuese eficaz solo con la primera fase -la declaración jurisdiccional-, ello solo sería oponible a las partes en el proceso de ejecución, mas no para el tercero adquirente, que se encontraría de buena fe, por lo que la nulidad absoluta del acto no podría ser declarada. Sobre este punto volveremos más adelante.

No obstante la noción que subyace en las normas comentadas, el artículo 453, inc. $1^{\circ}$ del CPC, pareciera establecer una totalmente diferente, al decir:

Si el embargo recae sobre bienes raíces o derechos reales constituidos en ellos, no producirá efecto alguno legal respecto de terceros sino desde la fecha en que se inscriba en el respectivo registro conservatorio en donde estén situados los inmuebles.

Según este artículo, la anotación registral del embargo solo tendría por objeto hacerlo extensivo a terceros.

Sin perjuicio de la aparente contradicción que se observa, puede concluirse prima facie que el embargo produce un efecto en el proceso de ejecución (interno) y otro fuera

${ }^{43}$ La parte final del artículo 450 fue agregada por el artículo $2^{\circ}$ de la Ley 18.735. 
de él (externo). El primero de ellos, dice relación con la afección de determinados bienes al proceso. Con el embargo los bienes trabados quedan atados al proceso, pasando a ser su objeto a través de una declaración judicial pronunciada en la ejecución. El segundo de ellos, consiste en una prohibición para los que no son partes en el proceso de concurrir a la distracción de los bienes desde el patrimonio del deudor. Este efecto que asegura la conservación de los bienes en la esfera de dominio del ejecutado, se manifiesta a través de un signo sensible externo al proceso: la anotación en el registro pertinente o la entrega de bienes al depositario.

Ahora bien, resulta indispensable para la correcta consecución del embargo que produzca eficazmente ambos efectos, tanto el interno al proceso como el externo a él. Solo así la declaración de afección cumplirá cabalmente su objeto de individualizar el bien o derecho sobre el que recaerá la actividad ejecutiva, e impedir que ellos puedan ser distraídos a terceros.

\section{LA ANOTACIÓN REGISTRAL COMO ELEMENTO INTEGRANTE DE LA TRABA}

Creemos que esta medida de garantía debe ser considerada como elemento integrante del embargo. Nos permite sostener lo anterior los siguientes argumentos:

a) Dentro de la estructura del embargo, podemos distinguir la fase de la traba y la de adopción de las medidas conservativas ${ }^{44}$.

Como señala un autor, los distintos momentos del embargo solo pueden ser aislados para efectos de su estudio, pero en la realidad se presentan entremezclados, sin que pueda esbozarse una línea divisoria entre ellas ${ }^{45}$.

Pues bien, en nuestro ordenamiento, por diversas razones, la dificultad para hacer esta distinción es todavía mayor. Carecemos de una definición legal de embargo, así como de una individualización clara de cada una de sus etapas, lo que obstaculiza su adecuado control. Por ende, si solo bastara la declaración jurisdiccional para tener por embargado un derecho, el juez ejecutor, los terceros y las partes carecería de los medios para controlar que se cumpla correctamente su materialización.

Es indispensable que el embargo se entienda trabado conjuntamente al adoptarse las medidas de garantía, solo así podrá controlarse adecuadamente la titularidad del bien y evitar su distracción. La adopción de estas medidas es básica: solo una vez adoptadas podrá verificarse la existencia real de los bienes afectados y quién es su dueño. Con la entrega de los bienes al depositario o con la anotación en el registro respectivo, el tribunal y la parte interesada podrá tener cabal conocimiento de la existencia del bien embargado, de su calidad y características. Esta cuestión reviste gran importancia especialmente cuando es el ejecutado quien ofrece bienes para ser realizados (art. 448 del $\mathrm{CPC}$ ), quien podría indicar bienes de un tercero, situación que podría solo develarse al adoptarse la medida conservativa correspondiente.

\footnotetext{
${ }^{44}$ Se pueden distinguir otras. v. gr. la de localización, búsqueda y selección de bienes.

45 Carreras, Jorge (1957) p. 128. En igual sentido, NaVArrete (2004) p. 59.
} 
b) La ley mariana sobre juicio ejecutivo, tuvo una enorme influencia en la regulación del embargo en el $\mathrm{CPC}^{46}$, estableciendo a partir del artículo 19 la forma como debía llevarse a cabo.

Según el artículo 6 No 1 de dicha ley, el mandamiento de ejecución debía contener la orden de embargar bienes en cantidad suficientes para cubrir la deuda y costas de la cobranza, los que debían ser depositados en persona de reconocida responsabilidad, "dejando trabada en ellos la ejecución". El acto del embargo podía ser presenciado por las partes, por sí o por sus apoderados, debiendo firmar la diligencia si sabían hacerlo. En caso contrario, "[h] echa la traba, se le notificará al deudor si no la hubiere presenciado,...”.

Así, la ley de 1837 exigía para tener por embargados los bienes, que estos sean depositados en persona de reconocida responsabilidad. De ahí el uso de la expresión "dejando trabada en ellos la ejecución".

Este principio contenido en la ley mariana sobre juicio ejecutivo, que se mantuvo en el artículo 450, inc. $1^{\circ}$, del CPC, al prescribir que el depósito forma parte integrante del embargo y que solo con la entrega los bienes al depositario se entiende practicada la traba, viene en establecer el principio rector en esta materia, también aplicable al embargo de bienes raíces o derechos reales constituidos sobre ellos: el embargo se materializa con la adopción de la medida conservativa.

En este sentido, resulta interesante tener presente que el proyecto de González solo impedía la enajenación de los bienes raíces embargados una vez efectuada la anotación del embargo en el registro respectivo (art. 900). De este modo en el plan del jurista colombiano, la finalidad conservativa del embargo, solo se lograba con esta inscripción; y su falta permitía a los terceros adquirir la propiedad sin que existiera sanción que lo impida.

c) Como señalamos el embargo no solo persigue determinar los bienes que serán objeto de la ejecución. Si así fuera, solo bastaría la declaración judicial en ese sentido.

El embargo, también permite al acreedor evitar que, durante la pendencia del proceso, los bienes que responderán de la deuda desaparezcan jurídica o materialmente. Dicha finalidad solo se logra con la adopción de las medidas asegurativas, sin las que el embargo es del todo inútil.

En este sentido, la Corte de Apelaciones de Santiago, confirmó, con costa, la sentencia del 220 Juzgado Civil de Santiago, que con fecha 30 de julio del año 1996 declaró:

Que es necesario tener presente que el embargo sobre un bien raíz se entiende que queda perfeccionado cuando esa medida cautelar genéricamente dicho se inscribe en el Registro de Interdicciones y Prohibiciones de Enajenar, y desde ese instante

46 MORA (1917) p. 53, señala que en las leyes marianas lo usual es "encontrarse con principios jurídicos idénticos, tal cual ahora figuran en nuestra lejislacion, o, si se nos permite, como en embrión, esbozados. Esta similitud es verdaderamente notable en la lei sobre el Juicio Ejecutivo como ya hemos podido ver u como seguiremos viendo". 
el deudor queda privado de la disposición del mismo, situación que no se demostró por el actor por ningún medio legal idóneo ${ }^{47}$.

De este modo, todos los efectos del embargo se verifican una vez adoptadas las medidas, pues solo a través de ellas el embargo "existe para el mundo". El embargo, a diferencia de la sentencia, produce efectos respecto de terceros; efectos cuya causa es la medida conservativa. Sin ellas no los produce, dejándolo trunco e infecundo.

d) El embargo no solo persigue determinar los bienes que estarán afectos a la realización y evitar su desaparición. Como dijimos, también tiene por objeto asegurar a los terceros que sus bienes quedarán a salvo de la ejecución.

Solo a través de la adopción de las medidas de garantía puede controlarse eficazmente esta cuestión, y evitar que los efectos de la traba se extiendan a terceros ajenos al proceso. Si el embargo se agota en la sola declaración jurisdiccional, este sería conocido únicamente por las partes en el proceso, y no por aquellos terceros que puedan verse perjudicados. La sola declaración judicial impide a los que no son parte en el proceso, incluso al dueño de los bienes afectados, percatarse de la extensión que ha adoptado el embargo. Evidentemente, esta situación ampara el fraude.

En cambio, la adopción de la correspondiente medida de conservación, sea el depósito o la anotación registral, permite al dueño del bien respectivo percatarse de la existencia del embargo y controlar, de modo eficaz, la existencia de un presupuesto esencial del embargo: que recaiga sobre bienes cuyo titular sea el ejecutado.

\section{LA INEXISTENCIA DE LA MEDIDA CONSERVATIVA IMPIDE DECLARAR LA NULIDAD ABSOLUTA DE LA ENAJENACIÓN}

Entre los fines del embargo se encuentra aquel consistente en impedir al deudor ejecutado enajenar sus bienes a terceros. En caso de que tal maniobra ocurra, deberá ser declarada absolutamente nula.

Los efectos de la nulidad declarada por sentencia judicial solo tienen fuerza obligatoria respecto de las causas en que actualmente se pronunciaren, esto es, con relación a las personas mismas que litigaron y a aquellos que según la ley aprovecha el fallo ${ }^{48}$.

Esta característica, expresamente reconocida en el artículo 1690 del CC, y los graves efectos que acarrea la nulidad, importan que en el proceso de nulidad deban ser parte, como demandante o demandado, todos aquellos que han celebrado el acto o contrato. Siendo los efectos de la nulidad indivisibles, esta no puede ser declarada solo respecto de algunos de los contratantes. En caso contrario, "se declararía nulo el contrato sin oír a uno de los afectados, y nadie puede ser condenado sin ser oído. Es imposible, además, que se declare nulo un contrato respecto de algunos que intervinieron en su celebración, y quede

47 Gaete Villaseñor, Guido con Banco de Chile (1996). La sentencia fue confirmada por la Corte de Apelaciones de Santiago, y el recurso de casación en el fondo interpuesto en contra de esta última declarado desierto.

48 Claro (1939) t. III, p. 633. 
subsistiendo válidamente respecto de otros que no fueron citados al juicio en que se discutió su validez, porque el contrato o es válido o es nulo respecto de todo el mundo, ya que se trata de un carácter propio del contrato, sin relación con determinadas personas” ${ }^{49}$.

Pues bien, siendo los efectos de la nulidad absoluta indivisibles, en el proceso en que se ejerce esta acción -imperativamente- deben intervenir todos aquellos que han celebrado el acto o contrato. En otras palabras, como la declaración de nulidad de un negocio trasciende a los derechos y títulos que le sirven de fundamento, la acción que la persigue debe intentarse contra todos los que puedan ser perjudicados por la pretendida declaración $^{50}$. Esto es, el ejercicio de la acción de nulidad da lugar a un litisconsorcio necesario.

Lo común es que en la legitimación ordinaria quien ejerce la acción señale ser el titular del derecho subjetivo ventilado en juicio (legitimación activa) y que la titularidad de la obligación corresponda al demandado (legitimación pasiva). Pero existen casos en que esta solución no es suficiente, debiendo considerarse -para que la legitimación pueda considerarse existente- que su vertiente activa se haga por varias personas o que la imputación se haga en contra de varias otras ${ }^{51}$, originándose un litisconsorcio. Esta situación puede venir porque la norma legal así lo disponga ${ }^{52}$, o bien, porque venga impuesta por la misma naturaleza de la relación material controvertida en juicio.

En el litisconsorcio necesario "se está en presencia de una sola acción que conforma el objeto del proceso, la que debe ser resuelta de un modo unitario para todos los sujetos que activa o pasivamente conforman la relación procesal" 53 . En el fondo, "[s]e trata de situaciones en las cuales la protección que el actor solicita del órgano jurisdiccional es de carácter indivisible o único para todos los litisconsortes, ya sea que ello venga establecido por la ley o la naturaleza misma de la relación de derecho material, situación que obliga a que concurran todos ellos al proceso, siendo además la sentencia que se dicte única para todos los litisconsortes" 54 . Del mismo modo, si son varios los que como demandante pueden verse afectados por la cosa juzgada, todos ellos deben intervenir en el proceso.

De este modo, la acción de nulidad genera uno de los casos prototípicos de litisconsorcio necesario. En este sentido, la Excma. Corte Suprema ha señalado:

La acción de nulidad de un contrato es una acción personal que debe interponerse en contra de todos los que fueron parte en el contrato que se pretende anular, toda vez, que de lo contrario y atento al efecto relativo de la sentencia judicial que se consagra en el artículo $3^{\circ}$ del Código Civil, resultaría que un mismo contrato sería nulo respecto de la parte en contra de la cual se intentó la acción y válido

\footnotetext{
49 AlesSANDri (2008) p. 583. En este sentido, Rodríguez, José con Martínez, Ezequiel (1989): “[1]os efectos relativos de las sentencias judiciales impiden declarar eventualmente la nulidad de un acto, si la acción no se ha dirigido en contra de todos los que intervinieron en él,...”.

50 De CASTRO (2002) p. 483.

51 Montero (1994) pp. 39 y 40.

52 Desconocemos en nuestro ordenamiento alguna norma que ordene proceder de esta forma, y que dé origen al denominado litisconsorcio necesario propio.

53 Romero (2000) p. 22. Sobre el litisconsorcio necesario, véase también ROMERO (1998).

54 Romero (2000) p. 22. En igual sentido: CORdón (1979) p. 330.
} 
respecto de la otra que no fue motivo de la demanda, lo cual repugna no solo al ordenamiento jurídico sino la lógica más elemental ${ }^{55}$.

De lo anterior se desprende que cuando se pretenda la nulidad del artículo 1464 No 3 CC, el interesado, generalmente el acreedor, debe ejercer su acción en contra del deudor que ha enajenado los derechos embargados y en contra del adquirente. El acto de enajenación no puede ser anulado solo respecto de uno de ellos, pues nos encontramos frente a una legitimación conjunta. Así, el correcto ejercicio de la acción de nulidad del artículo 1464 No 3 del CC implica tener presente que la posición habilitante para que contra alguien se formule la pretensión deba ser atribuida a varias personas de modo conjunto, el adquirente y el enajenante, de tal modo que si la pretensión no se hace frente a todos ellos no se cumple el presupuesto procesal de la legitimación ${ }^{56}$.

Debiendo ejercerse la acción de nulidad contra el deudor ejecutado y el tercero adquirente, cobra gran importancia la adopción de la medida conservativa pertinente. En caso de que ella no se haya materializado, la declaración de nulidad no prosperará, por cuanto el tercero adquirente podrá alegar, con razón, que el embargo no se entiende efectuado y que las declaraciones jurisdiccionales efectuadas a su consecución no le empecen.

Por lo anterior la adopción de la medida conservativa de que trata nuestro trabajo cobra esencial importancia. No habiéndose practicado la anotación registral, los efectos del embargo decretado no alcanzarán a los terceros; los que invocando una ignorancia excusable podrán evitar la nulidad absoluta que los amenaza y, conjuntamente con ello, evitar que se realice el efecto conservativo pretendido por el embargo y el consiguiente daño al ejecutante.

\section{CONCLUSIONES}

De lo expuesto, podemos concluir las siguientes cuestiones:

a) En nuestro ordenamiento civil el embargo tiene una finalidad conservativa: garantizar que los bienes trabados permanezcan bajo el dominio del deudor y sometidos al proceso de ejecución para la satisfacción del crédito.

\footnotetext{
55 Corporación de Fomento a la Producción (1990):

56 Del Campo Thorud, Edilio y otro con Undurraga Ossa, Sergio (1957): "Que como puede advertirse, el hecho básico en que se fundamentan todas las peticiones de la demanda lo constituiría la circunstancia de que a la época en que se celebró el contrato de compraventa entre doña Ana Undurraga Lazo, como vendedora, y don Sergio Undurraga Ossa, como comprador y único demandado en este juicio, el 3 de enero de 1949, como al practicarse la inscripción de dominio correspondiente en el Conservador de Quillota -el 12 de enero de 1949-, el inmueble objeto de la compraventa se encontraba embargado en juicio ejecutivo... 21 $1^{\circ}$ Que no obstante lo expuesto en el considerando anterior, cabe dejar constancia que en caso alguno podía prosperar la demanda instaurada en cuanto por ella se persigue la declaración de nulidad del contrato de compraventa alebrado entre doña Ana Undurraga Lazo y don Sergio Undurraga Ossa, en atención a que no se dirigió esa acción en contra de ambos contratantes sino que exclusivamente respecto de uno de ellos, el comprador, con lo cual el fallo que hubiera podido dictarse acogiendo la demanda habría resultado inoperante con relación a la vendedora doña Ana Undurraga, por no haber sido emplazada al juicio y no empecerle por consiguiente sus resultados”.
} 
b) Solo en la medida que la anotación registral del embargo sobre bienes inmuebles o derechos reales constituidos sobre ellos sea considerada como parte integrante de su estructura, la traba podrá producir eficazmente el efecto conservativo mencionado.

c) En la medida que el embargo sobre bienes inmuebles o derechos reales constituidos sobre ellos haya sido anotado en el registro conservatorio respectivo los terceros podrán tener conocimiento de la indisponibilidad que los afecta y que su enajenación puede ser declarada absolutamente nula.

d) La anotación registral permite al ejecutante como al juez ejecutor velar porque los bienes inmuebles embargados pertenezcan al deudor ejecutado.

\section{BIBILIOGRAFÍA CITADA}

Alessandri BesA, Arturo (2008): La nulidad y la rescisión en el Derecho Civil chileno (Santiago, Imprenta Universitaria, reimpresión, tomo 1).

Allende Castro, Salvador (1897): Algunas Observaciones sobre el inciso 3 del artículo 1464 del Código Civil (Imprenta de Donoso Hermanos, Santiago Memoria de prueba) $29 \mathrm{pp}$.

Benavente, Darío (1961): Derecho Procesal, Juicio Ejecutivo (Santiago, Edit. Universitaria S.A., apuntes revisados por A. Daudet) 187 pp.

Blest Gana, Joaquín (1871): Proyecto de Código de Enjuiciamiento (Santiago, Imprenta de La República) 93 pp.

Cachón Cadenas, Manuel-Jesús (1991) El Embargo (Librería Bosch, Barcelona,) 686 pp.

CARRERAS, Jorge (1957): El embargo de bienes (José Ma Bosch, Barcelona) 613 pp.

Casarino Viterbo, Mario (2007): Manual de Derecho Procesal (Santiago, Edit. Jurídica de Chile, 6a edc., tomo 5).

Claro Solar, Luis (1939): Explicaciones de Derecho Civil Chileno y Comparado (Santiago, Nacimiento, tomo 3).

CORdón Moreno, Faustino (1979): “Anotaciones acerca de la legitimación”, en Revista de Derecho Procesal Iberoamericana, Madrid, No 2, pp. 305-339.

De Castro y Bravo, Federico (1985): El Negocio Jurídico (Madrid, Civitas) 550 pp.

Espinosa Fuentes, Raúl (2003): Manual de Procedimiento Ejecutivo (Santiago, Edit. Jurídica de Chile, $11^{\text {a }}$ edc.) 239 pp.

FernándeZ, Miguel Angel; RifA, José María; Valls, José Francisco (1995): Derecho Procesal Práctico (Madrid, Centro de Estudios Ramón Arece S.A., tomo 5).

GonZÁlez, Florentino (1861): Proyecto de Código de Enjuiciamiento Civil para la República de Chile (Santiago, Imprenta Nacional) 339 pp.

Hevia Bolaños, Juan de (1853): La Curia Filipica (París, Librería de Rosa y Bouret) $612 \mathrm{pp}$.

JiméneZ Asenjo, Enrique (1956): El Embargo (Barcelona, Edit. Fco. Seix S.A.) 54 pp.

Lillo Hunzinker, Lenin (sin año): Manual de Procedimiento Ejecutivo (Santiago, Edit. Jurídicas de Santiago) 158 pp. 
LiRA, José Bernardo (1868): Prontuario de Juicios, (Santiago, Imprenta Nacional, tomo 3). MARÍn GONZÁLEZ, Juan Carlos (2004): Las Medidas Cautelares en el proceso civil chileno (Edit. Jurídica de Chile, Santiago) 489 pp.

Micheli, Gian Antonio (1970): Derecho procesal civil (Buenos Aires, Ediciones EuropaAmérica, trad. S. SENTís MELENDO, tomo 3).

Montero Aroca, Juan; Ortells Ramos, Manuel y Gómez Colmer, Juan-Luis (1991): Derecho Jurisdiccional (Barcelona, Bosch, tomo 2, volumen 1).

Mora Miranda, Marcial (1917): Historia del Derecho Chileno. Las Leyes marianas (Santiago, Imprenta Gutemberg, Memoria de Prueba) 67 pp.

NAVARRETE Villegas, Luis Gonzalo (2004): Embargo, tercerias, y realización de bienes (Santiago, Edit. Jurídica de Chile, 2a edc. ampliada y puesta al día) 373 pp.

Pereira AnAbalón, Hugo (1993) "Embargo y cautela en el proceso chileno", en Gaceta Jurídica, No 157 , pp. 7-25

Prieto Castro y Ferrándiz, Leonardo (1983): Derecho Procesal Civil (Madrid, Editorial Tecnos, $3^{a}$ ed. Reimpresión puesta al día, v. 2).

RIVEros IzQUierdo, Manuel Antonio (1964): El Embargo (Santiago, Edit. Jurídica de Chile) $102 \mathrm{pp}$.

Romero Seguel, Alejandro (2000), La Acumulación Inicial de Acciones (Artículos 17 y 18 del Código de Procedimiento Civil), (Santiago, ConoSur Ltda.) 159 pp.

Romero Seguel, Alejandro (1998): "El litisconsorcio necesario en el derecho procesal chileno. Doctrina y Jurisprudencia”, en Revista Chilena de Derecho, vol. 25 No 2, pp. 387-422.

Serra Domínguez, Manuel (1969): Estudios de derecho procesal (Barcelona, Ariel) 805 pp.

Sin autor (1884): Proyecto de Código de Enjuiciamiento Civil. Conforme los acuerdos hasta ahora celebrados por la comisión encargada de su examen (Santiago, Imprenta El Progreso, 4 v. en dos).

Sin autor (1902): Proyecto de Código de Procedimiento Civil revisado por la Comisión Mista de Senadores i Diputados (Santiago, Imp. Litografía i Encuadernación Barcelona) 470 pp.

TaVolari Oliveros, Raúl (2000): El proceso en acción (Santiago, Libromar Ltda.) 712 pp.

VArgas Fontecilla, Francisco (1867): Proyecto de Código de Enjuiciamiento Civil (Santiago, Imprenta Nacional) 55 pp.

VIERA, Luis Alberto (1949): Las medidas de garantía y embargo (Montevideo, Talleres Gráficos “33” S.A.) 100 pp.

\section{JURISPRUDENCIA CITADA}

Banco de Chile (1995): Corte Suprema, 27 de junio de 1995, Revista de Derecho y Jurisprudencia, t. $92 \mathrm{n}^{\mathrm{o}} 1$, sec. $1^{\mathrm{a}}$, pp. 49 y ss.

Corporación de Fomento a la Producción (1990): Corte Suprema, 8 de mayo de 1990, Revista de Derecho y Jurisprudencia, t. 87 no 1 , secc. $1^{\mathrm{a}}$, pp. 32 y ss. 
Del Campo Thorud, Edilio y otro con Undurraga Ossa, Sergio (1957): Corte de Apelaciones de Santiago, 16 de julio de 1957; Revista de Derecho y Jurisprudencia, t. 54, secc. $2^{\mathrm{a}}$, pp. 33 y ss.

Gaete Villaseñor, Guido con Banco de Chile (1996): Vigésimo Segundo Juzgado Civil de Santiago, 30 de julio de 1996; No Identificador Legal Publishing 24221-

Pinto con Rebolledo (1945): Corte de Apelaciones de Valdivia, 3 de diciembre de 1945; Revista de Derecho y Jurisprudencia, t. 43., secc. 2a, pp. 101 y ss.

Rodríguez, José con Martínez, Ezequiel (1989): Corte de Apelaciones de Santiago, 15 de junio de 1898, Revista de Derecho y Jurisprudencia, t. 86 no 1, secc. $2^{\mathrm{a}}$, pp. 51 y ss. 
